\title{
Magnetic Geared Radial Axis Vertical Wind Turbine for Low Velocity Regimes
}

\author{
Teow Wei $\mathrm{Wei}^{1}$ and Aravind $\mathrm{CV}^{1, *}$ \\ School of Engineering, Taylor's University, Malaysia.
}

\begin{abstract}
In the 21 st century, every country is seeking an alternative source of energy especially the renewable sources. There are considerable developments in the wind energy technology in recent years and in more particular on the vertical axis wind turbine (VAWT) as they are modular, less installation cost and portable in comparison with that of the horizontal axis wind turbine (HAWT) systems. The cut-in speed of a conventional wind turbine is $3.5 \mathrm{~m} / \mathrm{s}$ to $5 \mathrm{~m} / \mathrm{s}$. Mechanical geared generators are commonly found in wind technology to step up power conversion to accommodate the needs of the generator. Wind turbine gearboxes suffer from overload problem and frequent maintenance in spite of the high torque density produced. However, an emerging alternative to gearing system is Magnetic Gear (MG) as it offers significant advantages such as free from maintenance and inherent overload protection. In this project, numerical analysis is done on designed magnetic gear greatly affects the performance of the generator in terms of voltage generation. Magnetic flux density is distributed evenly across the generator as seen from the uniform sinusoidal output waveform. Consequently, the interaction of the magnetic flux of the permanent magnets has shown no disturbance to the output of the generator as the voltage generated shows uniform waveform despite the rotational speed of the gears. The simulation is run at low wind speed and the results show that the generator starts generating a voltage of $240 \mathrm{~V}$ at a wind speed of $1.04 \mathrm{~m} / \mathrm{s}$. This shows great improvement in the operating capability of the wind turbine.
\end{abstract}

\section{Introduction}

As oil reservoirs are running low and the increase in human population with demand, every country is seeking for an alternative source of energy especially the renewable energy sources. Due to the concerns on environmental issues, the development and application of renewable and clean energy are gaining more attention among the society. The wind technology and photovoltaic (PV) systems are found to be part of the two fast-growing technologies in the effort of generation of cleaner energy.

\footnotetext{
${ }^{1}$ Corresponding author: aravindcv@ieee.org
} 


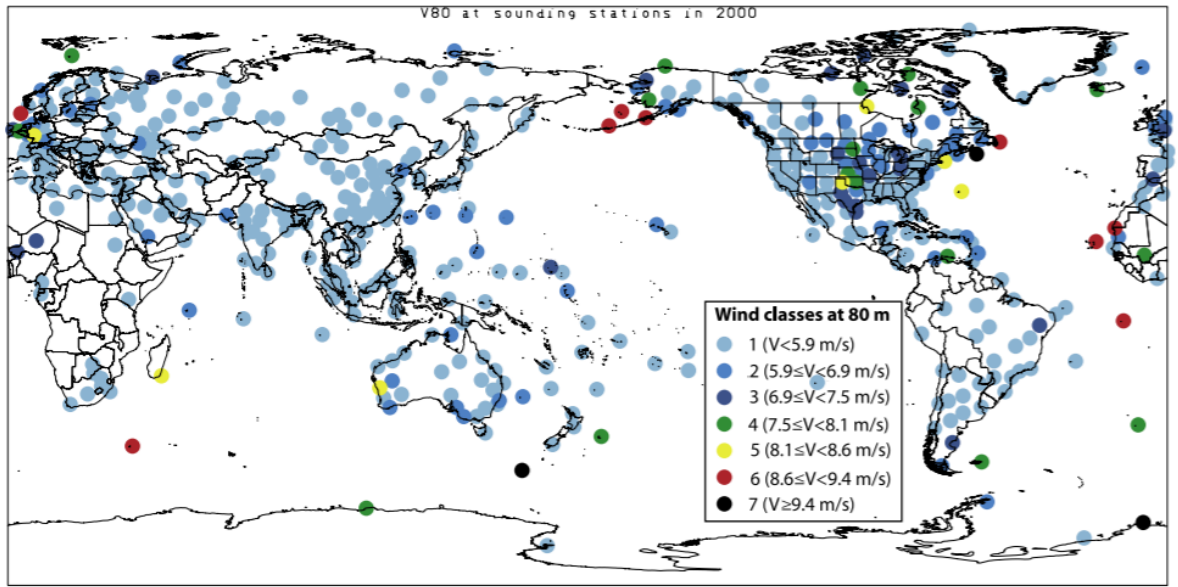

Fig. 1. World map of wind speed extrapolated to $80 \mathrm{~m}$ and the average for the year 2000 [2].

The only few countries with substantial wind speed are Japan, a few islands in China Sea, Guam and Mariana Islands. The majority of these areas are not suitable for wind power generation. Generally, Southeast Asia has poor wind potential on over $80 \%$ of the territory [2]. As seen in Figure 1.1, countries situated near or on the equator experience low wind speed due to the different direction of the wind that cancels on each other at the equator. Based on the wind speed characteristic of Malaysia recorded by the Malaysian Meteorological Department, typical wind speed ranges from as low as $0 \mathrm{~m} / \mathrm{s}$ to $13 \mathrm{~m} / \mathrm{s}$ with the highest mean daily wind speed of $3.8 \mathrm{~m} / \mathrm{s}$ recorded in Mersing, Johor [3]. Wind turbines in Mersing with a cut-in speed of $2.5 \mathrm{~m} / \mathrm{s}$ operate for 5084 hours a year [4]. Technically, the wind energy potential in Malaysia is very limited due to the low wind speed condition.

Industrial wind turbines fall into two general categories based on the axis of rotation of the wind turbine with respect to the ground surface and they are (a) horizontal axis wind turbine (HAWT), and (b) vertical axis wind turbine (VAWT). A conventional wind turbine has a cut-in speed of $3.5 \mathrm{~m} / \mathrm{s}$ to $5 \mathrm{~m} / \mathrm{s}$ and this is the minimum speed required to move the wind turbine blades into motion due to its inertia. At the rated speed of $12 \mathrm{~m} / \mathrm{s}$, the generator is operating in its ideal condition with the highest efficiency of power generation. When the wind speed is very high (above cut-out speed of $25 \mathrm{~m} / \mathrm{s}$ ), the wind turbine must be shut down due to mechanical constraints, while when the speed is very low (below cut-in speed), the operation is also in need of cutting off due to the variable low wind speed which is unable to move the generator at a constant speed. Many wind turbine system works on the principle of the wind energy conversion system (WECS) which can be divided into the aspects of aerodynamic, mechanical and electrical [5]. Critically optimizing each aspect helps in producing the most efficient output possible. WECS is projected and simplified in the form of block diagram as shown in Figure 2. 


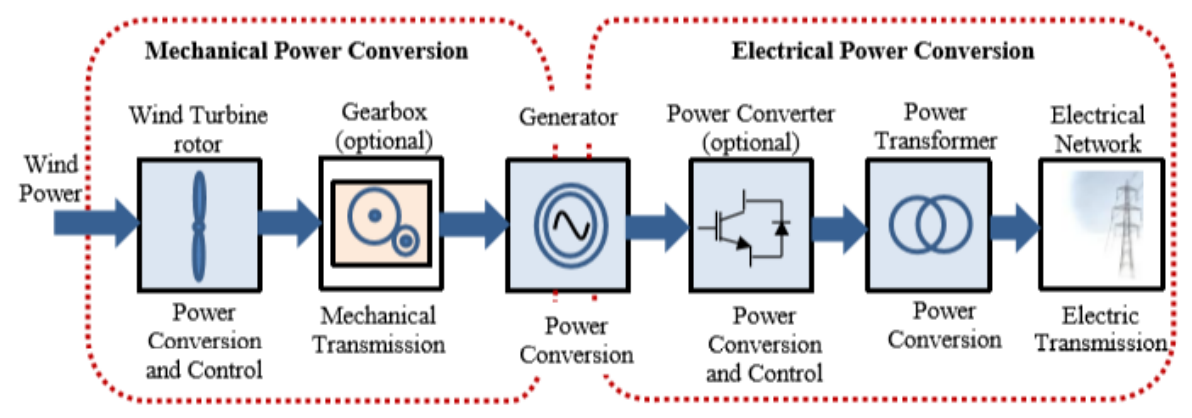

Fig. 2. Block diagram of WECS components viewed in aspects of mechanical and electrical [5].

High-speed electric generators are commonly found in many conventional wind turbines typically to step up the relatively low rotational speed of the rotor blades to accommodate the needs of the generator [8]. As a result, a gearbox is often used in the system to perform this function and since the speed increase needed is important, planetary mechanical gear type of configuration is oftentimes used to design the gearboxes of wind turbine [8]. Mechanical gears and gearboxes are commonly employed for speed change and torque transmission in various industrial applications [9], [10]. Many wind turbine gearboxes suffer from overload problem and frequent maintenance in spite of the high torque density produced by mechanical gears [9]. In contrast, an emerging alternative to gearing system is Magnetic Gear (MG) as it offers significant pros such as reduced noise and vibration, free from maintenance, and inherent overload protection [11]. In recent years, MGs have been widely used in the field of aerospace, marine-propulsion, and renewable energy [12]. Inspired by MGs, many Permanent Magnet (PM) machines with the integration of MGs are proposed to produce a higher power density than the conventional PM machines integrated with mechanical gears [12]-[14]. Nevertheless, MGs have yet to be seen to replace mechanical gears in the wind energy technology despite it being a promising technology for various torque-demanding applications due to the cost of permanent magnets[15-16].

\section{Theoretical Framework}

\subsection{Design Concept}

The conventional cut-in speed of a wind turbine is about $3.5 \mathrm{~m} / \mathrm{s}-5 \mathrm{~m} / \mathrm{s}$. A typical wind generator operates on the principle of motoring and generating. At speed lower than the cutin, the generator operates as a motor with the help of pitch control in order to put the stationary wind turbine into motion due to the naturally occurring inertia of turbine blades. Once it reaches the cut-in speed, the generator switches into two modes, generating and motoring. In this region, the motor continues to operate until the wind turbine acquires enough momentum to match the force provided by the wind speed. The machine then switches to full generation mode as the wind turbine is capable of rotating under the wind speed (also known as rated wind speed). The operational modes discussed above is portrayed below as shown in Figure 3. 


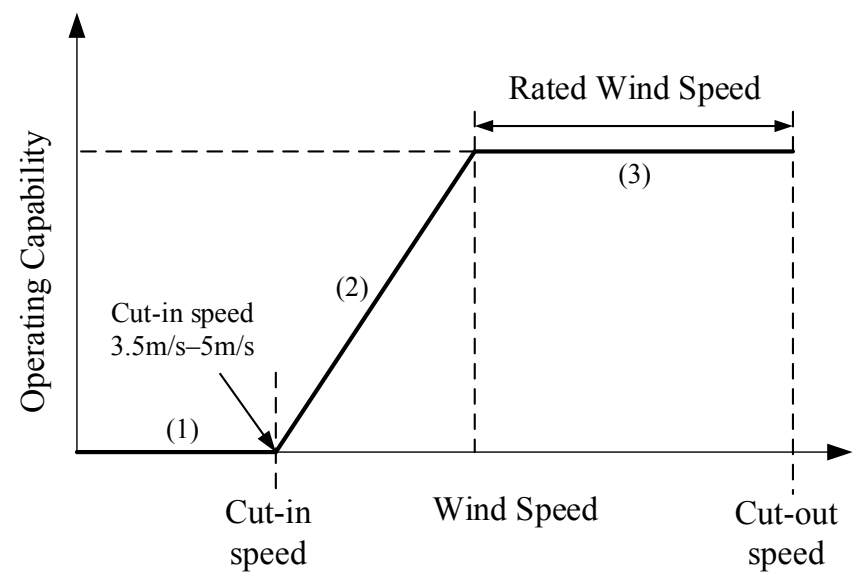

Fig. 3. Operational modes of a typical wind turbine.

Optimisation of the wind turbine system in the sense to increase the power generation capability on low wind speed condition is explained in Table 1 below.

Table 1. Optimised modes of wind turbine system.

\begin{tabular}{c|l}
\hline Mode & \multicolumn{1}{c}{ Description } \\
\hline $\begin{array}{c}\text { Motoring \& } \\
\text { Generating }\end{array}$ & $\begin{array}{l}\text { Power generation capacity is increased with the proposed magnetic gear even } \\
\text { under a low wind operating conditions with constant output. }\end{array}$ \\
\hline Generating & $\begin{array}{l}\text { In this mode, the operating mode is ideal and with the permanent magnet } \\
\text { used to integrate into magnetic gear configuration, constant speed of the } \\
\text { generator is able to be maintained. }\end{array}$ \\
\hline
\end{tabular}

The conventional mechanical structure of wind turbine system involves the use of mechanical gears and this is causing one of the major issues in the free revolution of turbine structure as the coupling between the gears induces some inertia to the system. Also, this results in the mechanical losses, friction, wear and tear due to which the gears are in contact. A magnetic gear, separated between the static structure and the revolving turbine, is proposed to address this concern. Figure 4 below shows the magnetic circuit of the ORIPMS generator and geared ORIPMS generator.

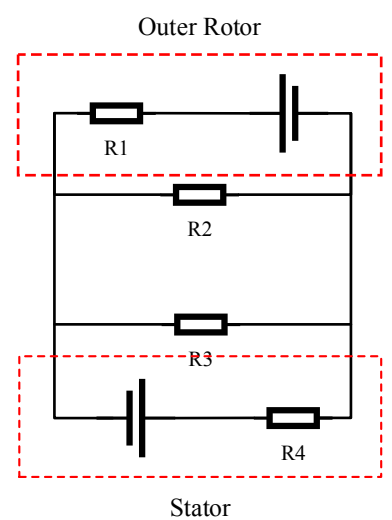

(a)

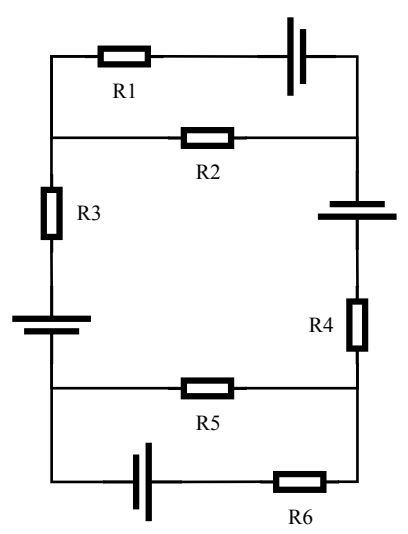

(b)

Fig. 4 (a) Equivalent magnetic circuit of ORIPMS. (b) Geared ORIPMS. 


\subsection{Magnetic Gear Ratio Design Concept}

In a geared wind turbine mechanism, mechanical gear ratio or transmission ratio is the ratio of a number of driver gear (attached to wind turbine) over the number of driven gear (attached to the generator). The magnetic gear transmission ratio is analogous to mechanical gear principle and is discussed in the following. The magnetic gear ratio is expressed in Equation (1).

$$
\text { Gear ratio, } \quad G_{r}=\frac{V_{\text {high }}}{V_{\text {low }}}=\frac{T_{\text {driving gear }}}{T_{\text {driven gear }}}=-\frac{N_{\text {low }}}{N_{\text {high }}}
$$

where $V_{\text {high }}$ and $V_{\text {low }}$ are rotational speed of high-speed gear and low-speed gear,

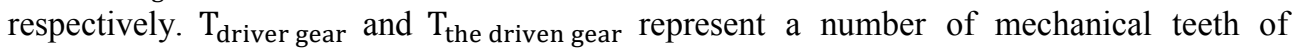
driver gear and driven gear, respectively. $\mathrm{N}_{\text {high }}$ and $\mathrm{N}_{\text {low }}$ are a number of pole-pairs of high-speed gear and low-speed gear, respectively. In order to attain the highest torque density, the number of pole pairs on each of the rotors should satisfy the following relation as in Equation (2).

$$
N_{\text {low }}=N_{\text {ferro }}-N_{\text {high }}
$$

where $\mathrm{N}_{\text {ferro }}$ is the number of ferromagnetic pole-pieces.

The selection of an appropriate combination of pole-pairs for the two rotating gears to produce a required gear ratio should take into consideration the torque ripples that may affect the performance of the magnetic gear. Torque ripple or cogging torque is caused by the interaction of the permanent magnets with the ferromagnetic pole-pieces. Therefore, cogging torque factor is defined to estimate the level of torque ripple on the performance (as shown in Equation (3)). The higher the factor, the higher the cogging torque is. The minimum value of this factor is unity $\left(C_{T}=1\right)$, which initiates a possible for good design selection as in Equation (3).

$$
C_{T}=\frac{N_{\text {high }} N_{\text {ferro }}}{\operatorname{LCM}\left(N_{\text {high }}, N_{\text {ferro }}\right)}
$$

\subsection{Relationship between the mechanical and electrical power in machine}

The mechanical power generated, $\mathrm{P}_{\text {gen,low }}$ by the low-speed gear is proportional to torque and speed of the gear, as shown in Equation (4).

$$
P_{\text {gen }, \text { low }}=T_{\text {low }} \cdot \omega_{\text {low }}
$$

where $\mathrm{T}_{\text {low }}$ is a torque generated by low-speed gear and $\omega_{\text {low }}$ is the angular velocity of the low-speed gear. As the speed the lower speed gear is proportional to the speed of higher speed gear with respect to the gear ratio, the relationship of the speeds affected by the gear ratio, $\mathrm{N}$ is as shown in Equations (5) and Equation (6).

$$
\begin{gathered}
v_{\text {low }} \propto v_{\text {high }} \\
v_{\text {low }}=G_{r} \cdot v_{\text {high }}
\end{gathered}
$$


As the speed is proportional to angular velocity, the mechanical power generated by the ring magnetic gear, $\mathrm{P}_{\text {gen,high }}$ is correlated to the gear ratio as shown in Equations (7) and Equation (8).

$$
\begin{array}{r}
P_{\text {gen,high }}=T_{\text {high }} \cdot \omega_{\text {high }} \\
P_{\text {gen,high }}=T_{\text {high }} \cdot G_{r} \cdot \omega_{\text {low }}
\end{array}
$$

where $\mathrm{T}_{\text {high }}$ is a torque generated by high-speed gear and $\omega_{\text {high }}$ is the angular velocity of the high-speed gear. Electrical power generated by the generator is expressed as in Equation (9).

$$
P=V \cdot I \cos \theta
$$

Mechanical power from the high-speed gear is converted directly to electrical power generated by the generator. With this, we can say that mechanical power is equal to the electrical power output and the relationship is expressed as in Equation (10).

$$
P_{\text {gen }, \text { high }}=P_{\text {elec }}
$$

By equating Equation (7) and Equation (8), we get power as in Equation (11).

$$
T_{\text {high }} \cdot G_{r} \cdot \omega_{\text {low }}=V \cdot I \cos \theta
$$

Therefore, by increasing the gear ratio of the magnetic gears, the electrical power output increase relatively. Outer Rotor Internal Permanent Magnet Synchronous (ORIPMS) generator (as shown in Figure 5) is used employed in this project due to its minimal ripple harmonics and a satisfactory amount of power produced. To further increase the efficiency of power produced by this generator, magnetic gear is introduced by increasing the flux density of the machine. FEM analysis is shown and analyzed in this section below. Comparison between the two models is done to observe the deviation of the results of the machines.

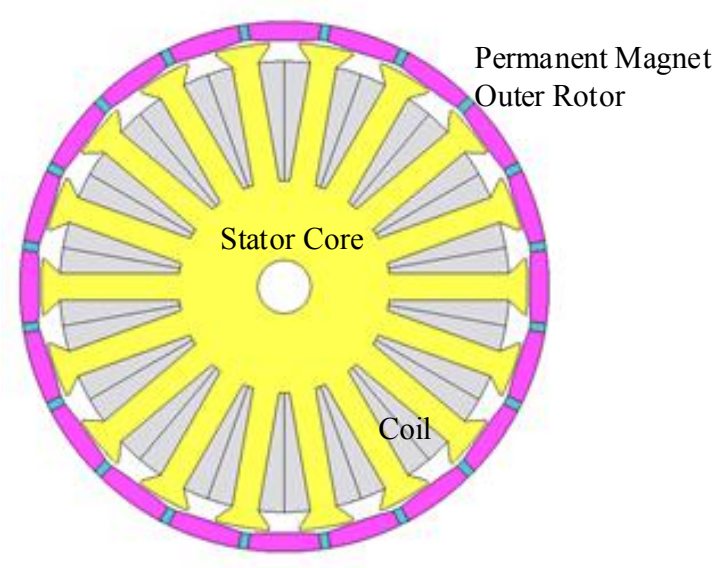

Fig. 5. Outer Rotor Internal Permanent Magnet Synchronous (ORIPMS) Generator. 
Table 2. Parameters of ORIPMS Generator.

\begin{tabular}{|l|c|}
\hline \multicolumn{1}{|c|}{ Parameter } & Value \\
\hline Number of poles on high-speed gear & 100 \\
\hline Number of ferromagnetic pole-pieces & 24 \\
\hline Number of poles on low-speed outer rotor & 20 \\
\hline Outer diameter of rotor & $50.0 \mathrm{~mm}$ \\
\hline Inner diameter of rotor & $46.5 \mathrm{~mm}$ \\
\hline Outer diameter of PM & $50.0 \mathrm{~mm}$ \\
\hline Inner diameter of PM & $47.0 \mathrm{~mm}$ \\
\hline Width of stator pole & $5.0 \mathrm{~mm}$ \\
\hline Width of stator teeth & $6.968 \mathrm{~mm}$ \\
\hline Length of stator pole & $22.5 \mathrm{~mm}$ \\
\hline Diameter of shaft & $5.0 \mathrm{~mm}$ \\
\hline Length of air gap & $0.5 \mathrm{~mm}$ \\
\hline Stack length & $50.0 \mathrm{~mm}$ \\
\hline Outer diameter of stator & $46.0 \mathrm{~mm}$ \\
\hline Inner diameter of stator & $5.0 \mathrm{~mm}$ \\
\hline Outer diameter of coils & $42.5 \mathrm{~mm}$ \\
\hline Inner diameter of coils & $20.0 \mathrm{~mm}$ \\
\hline PM pole-arc & 2 degrees \\
\hline Rotor pole-arc & 16 degrees \\
\hline Stator Teeth pole-arc & $13 \mathrm{degrees}$ \\
\hline
\end{tabular}

\section{Results and Discussion}

Magnetic flux density behavior of any generator is the primary evaluation that should be considered in designing a machine as this analysis fundamentally determines the output of the machine. In this project, the proposed magnetic gear has a direct interaction with the outer rotor permanent magnets and this might affect the output quality of the machine negatively. Through JMAG simulation, the magnetic flux density of the generator rotating at 500rpm and magnetic gear rotating at 100rpm with a gear ratio of 1:5 is shown in Figure 6. Fundamentally, the operation principle of a generator is defined by Faraday's Law, which states that electromotive force induced in a coil is proportional to the rate of change of the number of magnetic flux lines passing through the surface enclosed by the coil. Therefore, with this attribute, a sinusoidal induced output voltage is expected consequently and it is proven in the following section. The output voltage generated is presented with respect to different speed from $100 \mathrm{rpm}$ to $700 \mathrm{rpm}$. The voltage produced increases with the wind speed as graphed in Figure 7. Also, the generator starts generating voltage even at speed lower than the conventional cut-in speed of $3.5 \mathrm{~m} / \mathrm{s}$ to $5 \mathrm{~m} / \mathrm{s}$. The generator achieves a voltage of $240 \mathrm{~V}$ at speed of $200 \mathrm{rpm}$ or equivalent wind speed of $1.04 \mathrm{~m} / \mathrm{s}$ in which this is the standard voltage supply of household in Malaysia. This means that generating a voltage at low wind speed condition is achievable. As expected based on theoretical knowledge, the voltage generated increases with wind speed. The graph is increasing linearly from $0 \mathrm{~m} / \mathrm{s}$ to $2 \mathrm{~m} / \mathrm{s}$ but the graph deviates a little as the wind speed continues to increase. This is possible because the generator is starting to fall into the saturation region as the rated power of this machine is only $500 \mathrm{~W}$. 
Therefore, for this chosen generator, the size of it is only capable of low rotational speed. However, to increase its capacity, a small increment in diameter of the machine results in squared of the rated power. Based on the evaluation made above, it can be viewed that the operating range of wind turbine is improved on the low wind speed range. With this, the magnetic-geared generator enables the wind turbine to operate before the typical cut-in speed of $3.5 \mathrm{~m} / \mathrm{s}$ to $5 \mathrm{~m} / \mathrm{s}$. The conventional and optimized operating capability are illustrated in the following.

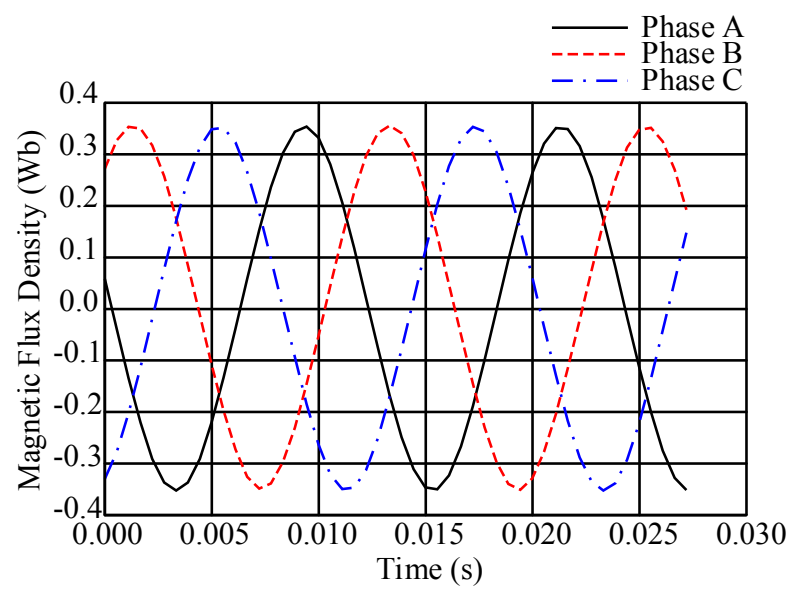

Fig. 6. The magnetic flux density of magnetic gear rotating at $100 \mathrm{rpm}$.

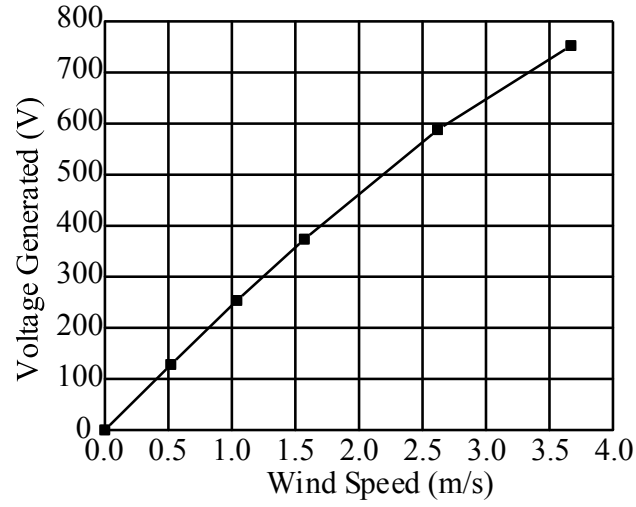

Fig. 7 Voltage generated at various wind speeds.

Table 3. Various speed versus voltage generated (rms).

\begin{tabular}{|c|c|c|c|c|c|c|}
\hline \multicolumn{2}{|c|}{ Speed (rpm) } & \multirow[b]{2}{*}{$\begin{array}{l}\text { Equivalent } \\
\text { wind speed } \\
(\mathrm{m} / \mathrm{s})\end{array}$} & \multicolumn{3}{|c|}{ Voltage Generated $\left(\mathrm{V}_{\mathrm{rms}}\right)$} & \multirow{2}{*}{$\begin{array}{c}\text { Average } \\
\text { RMS } \\
\text { Voltage } \\
\left(\mathrm{V}_{\text {rms }}\right)\end{array}$} \\
\hline $\begin{array}{c}\text { Magnetic } \\
\text { Gear }\end{array}$ & $\begin{array}{c}\text { Generator } \\
\text { Outer } \\
\text { Rotor } \\
\end{array}$ & & Phase A & Phase B & Phase C & \\
\hline 100 & 500 & 0.52 & 129.801 & 123.860 & 130.585 & 128.082 \\
\hline 200 & 1000 & 1.04 & 253.614 & 253.385 & 253.883 & 253.627 \\
\hline 300 & 1500 & 1.57 & 375.507 & 370.097 & 375.525 & 373.710 \\
\hline 500 & 2500 & 2.62 & 588.734 & 585.307 & 589.443 & 587.828 \\
\hline 700 & 3500 & 3.67 & 752.875 & 751.108 & 753.968 & 752.650 \\
\hline
\end{tabular}




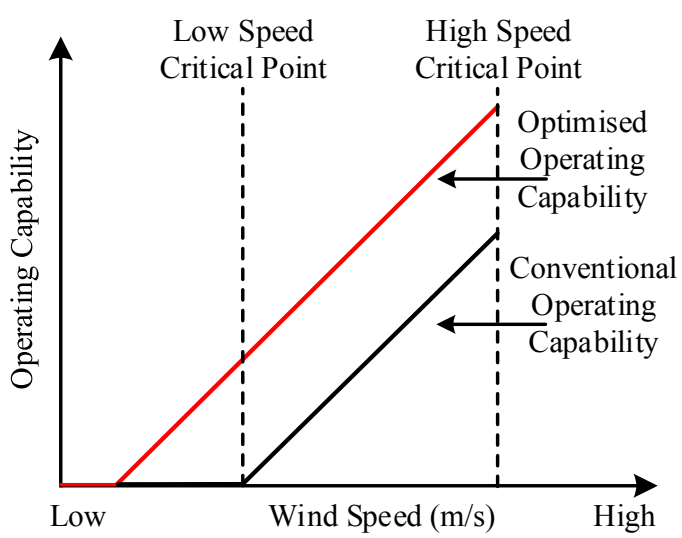

Fig. 4.3: Illustration of optimized operating capability

\section{Conclusion}

Magnetic flux density is distributed evenly across the generator as seen from the uniform sinusoidal output waveform. Consequently, the interaction of the magnetic flux of the permanent magnets has shown no disturbance to the output of the generator as the voltage generated shows uniform waveform despite the rotational speed of the gears. The simulation is run at low wind speed and the results show that the generator starts generating a voltage of $240 \mathrm{~V}$ at a wind speed of $1.04 \mathrm{~m} / \mathrm{s}$. This shows great improvement in the operating capability of the wind turbine and the objective of this project has been achieved.

\section{References}

[1] J. Damota, I. Lamas, A. Couce, J. Rodríguez. Vertical Axis Wind Turbines : Current Technologies and Future Trends, Int. Conf. Renew. Energies Power Qual. - La Coruña (Spain), 25th to 27th March, 2015, 1, no. 13, p. 6, (2015)

[2] C. L. Archer. Evaluation of global wind power, J. Geophys. Res., 110, D12, D12110 (2005)

[3] General Climate Information - Malaysian Meteorological Department, 2016 [Available online http://www.met.gov.my/in/web/metmalaysia/climate/climatechange/climateinformat ion. [Accessed: 14-Nov-2017].

[4] A. Belhamadia, M. Mansor, M. A. Younis. A study on wind and solar energy potentials in Malaysia, Int. J. Renew. energy Res., 4,no. 4, pp. 1042-1048 (2014)

[5] M. R. M. Altimania, Modeling of Doubly-Fed Induction Generators Connected to Distribution System based on eMEGASim ${ }^{\circledR}$ Real-Time Digital Simulator, J. Chem. Inf. Model., 53, no. 9, pp. 1689-1699 (2013)

[6] G. Semrau, S. Rimkus, T. Das, Nonlinear Systems Analysis and Control of Variable Speed Wind Turbines for Multiregime Operation, J. Dyn. Syst. Meas. Control, 137, no. 4 (2015)

[7] M. H. Chiang, A novel pitch control system for a wind turbine driven by a variablespeed pump-controlled hydraulic servo system, Mechatronics, 21, no. 4, pp. 753761, (2011)

[8] C. Nutakor, A. Klodowski, J. Sopanen, A. Mikkola, J. I. Pedrero, Planetary gear sets power loss modeling: Application to wind turbines, Tribol. Int., 105, pp.42-54 (2016) 
[9] K. Atallah, D. Howe, A novel high-performance magnetic gear, IEEE Trans. Magn., 37, no. 4, pp. 2844-2846 (2001)

[10] K. Atallah, J. Wang, D. Howe, A high-performance linear magnetic gear, J. Appl. Phys., 97, no. 10, pp. 26-29 (2005)

[11] W. H. X. Li, K.-T. Chau, M. Cheng, Comparison of magnetic-geared permanent magnet machines, Prog. Electromagn. Res., 133, pp. 177-198 (2013).

[12] S. Niu, Y. Mao, A Comparative Study of Novel Topologies of Magnetic Gears," Energies, 9, no. 10, pp.no. 773, (2016)

[13] W. Li, K. T. Chau, J. Z. Jiang, Application of linear magnetic gears for pseudodirect-drive oceanic wave energy harvesting, IEEE Trans. Magn., 47, no. 10, pp. 2624-2627 (2011)

[14] S. Niu, S. L. Ho, W. N. Fu, Performance analysis of a novel magnetic-geared tubular linear permanent magnet machine, IEEE Trans. Magn., 47, no. 10, pp. 3598-3601 (2011)

[15] M. M. Moh Saad, N. Asmuin, Comparison of Horizontal Axis Wind Turbines and Vertical Axis Wind Turbines, IOSR J. Eng., 4, no. 8, pp. 2250-3021, (2014)

[16] M. Mohd Amin, C. Chin, V. Garaniya, Application of Alternative Energies in the Australian Offshore Sector, Journal of Engineering Science and Technology, 11, no. 9, pp. 1296 - 1310 (2016)

[17] P. Sharma, T. Bhatti, K. Ramakrishnan, Permanent-Magnet Induction Generators: an Overview, Journal of Engineering Science and Technology, 6, no. 3, pp. 332 - 338 (2011) 